\section{artelogie}

\section{Artelogie}

Recherche sur les arts, le patrimoine et la littérature de l'Amérique latine

\section{$9 \mid 2016$}

Horizons et perspectives de la culture en Colombie (1990-2015)

\title{
Negra menta: por un reconocimiento a la mujer afrocolombiana
}

Adriana Pena Mejía

\section{OpenEdition}

Journals

Edición electrónica

URL: http://journals.openedition.org/artelogie/322

DOI: 10.4000/artelogie.322

ISSN: 2115-6395

Editor

Association ESCAL

Referencia electrónica

Adriana Pena Mejía, « Negra menta: por un reconocimiento a la mujer afrocolombiana », Artelogie [En línea], 9 | 2016, Publicado el 20 junio 2016, consultado el 17 noviembre 2020. URL : http:// journals.openedition.org/artelogie/322 ; DOI : https://doi.org/10.4000/artelogie.322

Este documento fue generado automáticamente el 17 noviembre 2020.

Association ESCAL 


\title{
Negra menta: por un reconocimiento a la mujer afrocolombiana
}

\author{
Adriana Pena Mejía
}

1 Partiendo de la obra Negra menta de Liliana Angulo Castro, se busca comprender la manera cómo los cambios impulsados por la Constitución Política de Colombia de 1991 participaron en la configuración de la identidad afrocolombiana de la artista. Realizada en el 2000 y constituida por deciocho fotografías a color, Negra menta propone deconstruir los estereotipos adosados tradicionalmente a la mujer afrocolombiana reflexionando sobre el imaginario colectivo que los alimenta. De esta investigación, se concluye que Negra menta fue efectivamente la heredera de los avances realizados en la década de los noventa por las nuevas preocupaciones multiculturalistas del Estado. Sin embargo, la obra cuestiona también la invisibilidad en el que siguen estando las comunidades afrocolombianas después de la Constitución de 1991.

2 Partant de l'œuvre Negra menta de l'afro-colombienne Liliana Angulo Castro, nous cherchons à comprendre la manière dont les changements stimulés par la Constitution Politique de Colombie de 1991 ont participé à la configuration de l'identité afrocolombienne de l'artiste. Realisée en l'année 2000 et constituée de 18 photographies, Negra menta propose de déconstruire les stéréotypes attribués traditionnellement à la femme afro-colombienne en réfléchissant sur l'imaginaire collectif qui les alimente. De cette recherche, nous concluons que Negra menta a été effectivement l'héritière des avancées réalisées durant la décennie de 1990 par les nouvelles préoccupations multiculturalistes de l'État. Cependant, Negra menta critique aussi l'invisibilité dans laquelle les communautés afro-colombiennes continuent à vivre bien après la Constitution de 1991. 


\section{Introducción}

3 El presente artículo busca comprender de qué manera el marco jurídico y social ofrecido por la Constitución Colombiana de 1991 participó en la configuración tanto de la identidad como de la obra plástica de la afrocolombiana Liliana Angulo Castro, quién busca deconstruir los clichés y los estereotipos atribuidos a las mujeres afrodescendientes retomando el imaginario colectivo que se tiene de ellas. Iniciaremos relacionando diferentes opciones teóricas para construir un marco de comprensión que nos permita dilucidar las condiciones de creación y producción de la obra de Liliana Angulo. Tomando como caso de estudio la obra Negra menta (2000, Banco de la República de Colombia) de la mencionada artista, analizaremos después cómo su obra responde a una necesidad de autoafirmación alimentada por las políticas multiculturalistas de la década de los noventa. Ocupando un lugar particular en el imaginario y en la memoria colectiva, la identidad afrocolombiana llegó a convertirse en un componente esencial del relato nacional como lo prueban expresiones populares como las cantantes Leonor González Mina, Toto La Momposina o el afamado grupo de música Hip Hop Choquibtown. Dialogando con la obra de artistas afroamericanas, terminaremos analizando la manera cómo Angulo descoloniza los códigos y los clichés imputados a la mujer afrocolombiana profundizando en las fotografías pertenecientes a la serie Negra menta.

La obra de Angulo nace dentro de las dinámicas y cambios ofrecidos por los nuevos lineamientos de la Constitución de 1991, en donde la defensa, el reconocimiento de las minorías étnicas y la equidad de género constituyeron elementos revolucionarios que sobrepasaron la esfera jurídica como lo demuestra el impulso de los estudios sobre las comunidades afrodescendientes (RESTREPO, 2001: s.p.). Gracias a la Constitución de 1991 y a la Ley 70 del 1993 sobre las negritudes ", "se abrieron otros escenarios y surgieron nuevas herramientas para pensar el papel de lo afro en la cultura colombiana" (GIRALDO, 2014: 85). Estos cambios permearon la propuesta de Angulo quién decidió romper con los códigos morales y estereotipos sociales presentes dentro de la sociedad colombiana afirmando su identidad y su condición de mujer afrocolombiana (JARAMILLO, 2015: 77).

\section{Lineamientos teóricos}

5 La Constitución de 1991 es concebida por las minorías como un punto de partida hacia la participación e inclusión política. Dentro de una crisis general alimentada por el narcotráfico, la corrupción y las confrontaciones armadas, la Constitución de 1991 emergió como una plataforma política y jurídica en la que se buscaba contrarrestar la constante violación a los derechos humanos (ESCOBAR, 2010: 239). Surgiendo también por necesidades externas impuestas por el fortalecimiento del mercado neoliberal latinoamericano, la Constitución conjugó por primera vez los intereses de diferentes identidades como proyecto político y se admitió una nación multirracial y multicultural. Sin embargo, la invisibilidad y la segregación siguieron presentes impidiendo la verdadera inclusión de los afrocolombianos, lo que generó el aumento de las inequidades sociales y la erosión de la estructura social (AROCHA, 1998: s.p.). La Constitución de 1991 introdujo además cambios positivos con respecto a los principios constitucionales y los derechos fundamentales de las mujeres. Los artículos 40, 43 y 53, 
por ejemplo, pregonan la igualdad de derechos y oportunidades laborales, castiga cualquier clase de discriminación y otorga apoyo de manera especial a las mujeres. Reconociendo la existencia de un desnivel y de diferencias históricas entre hombres y mujeres, la Constitución deja de concebir la mujer como un sujeto para proteger, para admitirla más bien como un sujeto titular y autónomo (WILLIS, 2007: 187-188).

Los logros realizados por el movimiento de mujeres en Colombia para 1991 son herederos de las luchas comprometidas de los grupos feministas de la década de los setenta (GOMEZ CORREAL, 2011: 176-188). La conformación de los grupos feministas colombianos en un período de convulsión donde el hippismo se posicionaba como filosofía de vida, donde la liberación sexual lideraba uno nuevo gesto ante la sociedad y donde mayo de 1968 constituía un nuevo pensamiento político, fue esencial para que en los años posteriores se descolonizara el sistema patriarcal que había generado esos movimientos feministas. Para esa misma época, las afrodescendientes y las chicanas en los Estados Unidos comenzaron a cuestionar fuertemente el racismo del feminismo blanco "al plantear que en los análisis y en las estrategias del movimiento no se consideraban realidades de muchas mujeres que además del género, le atraviesa la "raza" y la clase". Se dejó entonces de concebir la mujer como sujeto "universal", para pensarlo dentro de una pluralidad mucho más compleja.

$7 \quad$ En su texto Under Western Eyes, Chandra Talpade Mohanty explica que muchos de los estudios feministas que pretenden comprender las dinámicas sociales de las mujeres de países en desarrollo continúan reproduciendo y autorizando el discurso occidental blanco (TALPADE MOHANTY, 1991: 52-53). Ella argumenta que la consolidación de un tipo de etnocentrismo universal y la inadecuada resonancia de los discursos occidentales han generado una noción reductiva y homogénea del "Otro" que ella denomina "Third World Difference". Se ha académicamente asumido que la mujer del Tercer Mundo pertenece a un grupo históricamente constituido en donde no tiene poder, es explotada y menospreciada. Sin tener en cuenta las diferencias de clases, religiones, culturas, castas, etnias, etc., se ha encasillado a la mujer dentro de procesos de homogenización y sistematización que deben ser reevaluados y redefinidos.

Es dentro de esta redefinición académica que el libro de Gloria Anzaldúa, Crossing Borders: The new Mestiza, es importante. A lo largo del mismo, la académica resalta la implicación que las fronteras físicas, espirituales, raciales o políticas tienen sobre la conformación cultural de una identidad. Creadas y herederas de una colonización corrosiva, las fronteras que dividen la actual sociedad latinoamericana y por extensión la colombiana, constituyen el marco referencial de un estilo de vida particular donde la religión y la falsa moralidad dominan. Una "frontera", dice Anzaldúa, es una línea divisoria que distingue un nosotros de un ellos. Una "zona fronteriza" es, por consecuencia, un lugar indeterminado creado por los residuos emocionales que produce la "frontera". Tanto aquí como allá, lo prohibido y los "atravesados" es decir lo diferente, lo mulato, lo negro, lo indígena, el transexual, el inmigrante, el chicano, el homosexual, etc., conviven. Vedados de entrar y de salir, los "atravesados" están obligados a sobrevivir dentro de un entorno donde los paradigmas dominantes impuestos por el hombre y los conceptos predefinidos existen sin ser cuestionados. Un entorno donde las leyes hechas por los hombres son transmitidas por las mujeres y seguidas por los otros "atravesados" (ANZALDUA, 1987: 38-39). En concordancia con la visión de Anzaldúa y de Mohanty, la feminista brasileña Sueli Carneiro expone la importancia de concebir la mujer dentro su completa diversidad: 
Cuando hablamos del mito de la fragilidad femenina que justificó históricamente la protección paternalista de los hombres sobre las mujeres, ¿de qué mujeres se está hablando? Nosotras - las mujeres negras - formamos parte de un contingente de mujeres, probablemente mayoritario, que nunca reconocieron en sí mismas este mito, porque nunca fueron tratadas como frágiles. Somos parte de un contingente de mujeres que trabajaron durante siglos como esclavas labrando la tierra o en las calles como vendedoras o prostitutas. Somos parte de un contingente de mujeres con identidad de objeto. Ayer, al servicio de frágiles señoritas y de nobles señores tarados. Hoy, empleadas domésticas de las mujeres liberadas (CURIEL, 2002: 102).

Cuestionando la supuesta "fragilidad femenina", Carneiro reflexiona a la par sobre la vigencia de los postulados que enmarcan a la mujer dentro de las mismas luchas haciendo caso omiso de sus múltiples diferencias e intereses. No es lo mismo ser una mujer afrodescendiente viviendo en los suburbios de Chicago o de la Habana que ser una mujer proveniente del Pacífico Colombiano. Compartiendo la crítica realizada por la brasileña, Ochy Curiel se interroga sobre la estrategia más políticamente correcta que, sin ser esencialista, desvanezca los estereotipos y fracture las posiciones marginales impuestas por el sistema patriarcal, blanco, heterosexual y burgués occidental. Para Curiel, una de las estrategias es la autoafirmación que aparece "como una parte importante en tanto reconocimiento de una historia de subordinación, de vínculos familiares y de construcciones de las subjetividades, siendo estos elementos constitutivos de la identidad." (CURIEL, 2002: 106). En pocas palabras, la historia individual como colectiva y el reconocimiento positivo de un origen negro se convierten en elementos imprescindibles para un trabajo de autoafirmación.

Antes de entrar a analizar la obra de Liliana Angulo Castro es necesario traer a colación el reconocido texto de Linda Nochlin, Why have there been no great women artists? Escrito en 1971, la historiadora de arte americana se concentra en desmantelar el mito del artista genio mostrando que el sistema patriarcal y sexista occidental no ha permito a las mujeres artistas tener las mismas oportunidades que sus colegas masculinos. La mayoría de las artistas mujeres famosas, dice Nochlin, han tenido que rebelarse para delinear su camino profesional renunciando, muchas veces, al papel de ser madres, esposas e incluso hijas. Nochlin menciona, por ejemplo, el caso de Rosa Bonheur quien, a pesar de haber sido una de las artistas más reconocidas mundialmente fue fuertemente juzgada por haber rechazado numerosas propuestas de matrimonio (NOCHLIN, 1973: 30-37). Si para las artistas mujeres blancas ha sido largo y espinoso el camino hacia el éxito y al reconocimiento, ¿cómo ha sido el trayecto para las artistas afrodescendientes, para las chicanas, para las latinoamericanas, por nombrar sólo algunas? Dentro de un mundo globalizado en el cual la dicotomía centro/periferia (APPADURAI, 2010: 4-13) ha sido extensamente debatida, ¿en dónde se posicionaría la obra de una mujer afrocolombiana con respecto a la de una afroamericana o africana? En su libro Vision and Difference, Griselda Pollock considera que el énfasis en las representaciones culturales y en la construcción sexual de la diferencia son dos puntos claves para intervenir en la historia oficial del arte. Estos dos elementos de análisis permiten, según Pollock, el reconocimiento de los mecanismos y las relaciones de poder que sostienen y mantienen la diferencia sexual (POLLOCK, 1988: 9-17). La conjunción de estos dos elementos nos permitiría comprender, en el caso de mujeres artistas afrodescendientes, cómo la deconstrucción desde adentro, es decir desde el campo del arte, puede ser una estrategia discursiva para desmantelar los códigos socialmente establecidos y trastornar desde el interior del sistema patriarcal la manera en que la mujer del Tercer Mundo es concebida. 
11 Lo anterior nos permite tener un marco referencial para analizar la obra de Liliana Angulo Castro, quién ha desarrollado en la última década un trabajo plástico donde la exploración de la identidad afrocolombiana y su representación social se convierten en puntos centrales de cuestionamiento. Su trabajo se inscribe en un período en el cual "lo Otro interno", es decir el indígena y la mujer afrodescendiente, entre otros, adquieren un cierto respaldo legal y una mediación mediática gracias a la Constitución de 1991. En su obra, Angulo rescata los elementos culturales de las comunidades afrocolombianas y se interroga sobre las representaciones sexistas y racistas que los cuerpos de las mujeres afrodescendientes han sido objeto desde la colonia hasta nuestros días. Desde la Grecia antigua el "cuerpo ejemplar" es aquel que corresponde a las pautas admitidas por las autoridades políticas y religiosas. El hombre joven blanco occidental constituye el paradigma a seguir y lo que es diferente es una completa herejía. Los cuerpos de mujeres afrodescendientes "re-presentados" por Angulo no corresponden al sistema occidental patriarcal legado por la colonización española. De esta manera, las mujeres de Angulo violan la supremacía masculina, su color de piel rompe con el dominio blanco y su origen popular fractura el modelo burgués occidental (GIRALDO, 2014: 11).

El artículo transitorio 55 de la Constitución Política de Colombia de 1991 permitió el reconocimiento de las comunidades negras del Pacífico como propietarias de territorios colectivos y aprobó la participación de sus representantes ante los diferentes estamentos oficiales. Con el artículo 55 y la subsiguiente Ley 70 de 1993 (CONSTITUCION POLITICA DE COLOMBIA, 1991: 212), la región del Pacífico Colombiano, conformada en su gran mayoría por comunidades afrodescendientes, experimentó la configuración de nuevas formas de identidades inexistentes anteriormente. Según Arturo Escobar, con la nueva Constitución hubo un "re-descubrimiento" tanto externo como interno de los afrodescendientes colombianos. Gobierno, activistas, ONGs, movimientos de mujeres y líderes locales comenzaron a reflexionar conjuntamente sobre el lugar que ocupan los afrodescendientes dentro de la nación colombiana. Hubo una "reubicación y reaparición de lo negro" que permitió paralelamente la construcción de un nuevo sujeto político, las “comunidades negras” (ESCOBAR, 2010: 232).

13 Como lo advierte Escobar, el Pacífico Colombiano adquiere también gran importancia durante la década de 1990 por el interés que los recursos naturales despertaron en las multinacionales. La Región del Pacífico Colombiano reúne cinco departamentos: Chocó, Valle del Cauca, Nariño, Cauca y una parte de Antioquia. Además de ser habitado por una importante población afrocolombiana, allí viven pueblos nativos como los Awa, Cañamomo, Emberá, los Wounann y los Kunas ${ }^{2}$. La región concentra la segunda reserva natural más grande del planeta, después de la Amazonía (territorio colombiano compartido por Brasil y Perú). Denominada Chocó Biogeográfico, ésta región y sus riquezas biológicas han sido destruidas sistemáticamente a causa de la deforestación, de las prácticas agrarias insostenibles, la pesca ilícita y sobre todo el trabajo minero ilegal. A parte de la destrucción ecológica, los habitantes de esta región sufren incursiones violentas por parte de las guerrillas, los paramilitares y los diferentes grupos al margen de la ley. Una de las tantas irrupciones fue realizada el 2 de mayo de 2002, cuando la FARC (Fuerzas Armadas Revolucionarias de Colombia) lanza un cilindro bomba dentro de la iglesia de Bojayá, pueblo del departamento del Chocó, matando 119 personas y ocasionando el desplazamiento de numerosas familias (INFORME DEL GRUPO DE MEMORIA HISTORICA, 2010: 35-80) ${ }^{3}$. 
14 Dos años antes de la masacre y denunciando visualmente la grave situación de la población afrocolombiana, Liliana Angulo realiza Negra menta. Dividida en deciocho fotografías a color, la artista presenta las diferentes maneras a través de las cuales la sociedad colombiana identifica a la mujer afrodescendiente. La obra posee varios registros de lectura que reunidos cuestionan por un lado la construcción de una identidad nacional basada en la segregación racial, y por otro lado, señala los estereotipos sexistas anclados en la conciencia colectiva colombiana. Comenzando por el título Negra menta, Angulo juega con el significado de las palabras, al igual que lo hizo Joseph Kosuth en su obra One and three chairs de 1965. Mientras que Kosuth representa la silla en tres diferentes maneras (objeto, fotografía y el significado del diccionario) con la intención de explorar formas de concebir un solo objeto. Angulo, al contrario, toma una sola palabra que contiene tres significados distintos. Dentro del contexto social colombiano, Negramenta - en su modalidad pegada - es una palabra peyorativa que hace referencia a la comunidad negra en general. De hecho, el Diccionario de la Real Academia Española lo certifica: “conjunto de personas de raza negra” ${ }^{4}$.

Negra menta hace referencia, en segundo lugar, a un juego de palabras en donde la menta se convierte en un elemento de referencia geográfico puesto que la hierba proviene originalmente del Norte de África. A parte de sus beneficios higiénicos, la menta ha sido utilizada por sus propiedades curativas. Para la población afrocolombiana, la protección del territorio y todo lo que éste proporciona, incluyendo las hierbas medicinales, hace parte de su herencia ancestral. Tristemente, el modelo desarrollista impulsado por los Gobiernos ha generado una gran pérdida de recursos naturales renovables. El bosque húmedo del Pacífico y todas las plantas que éste produce se encuentra en amenaza de desaparición (BOTERO, 2010: 8-14).

Negra menta nos recuerda igualmente a Nieves quien es una caricatura creada en 1968 por Consuelo Lagos ${ }^{5}$ y mostrada en los principales periódicos del país como El Espectador y El País. En su texto La "negra nieves" ou le racisme à fleur de peau. Regards croisés sur une caricature, Elisabeth Cunin realiza un estudio alrededor de esta caricatura en donde reflexiona sobre las categorías "raciales" en Colombia (CUNIN, 2016: s.p). Oponiendo su nombre "blanco" a su pertenencia racial "negra", Nieves es una caricatura que representa una mujer afrodescendiente originaria de una región húmeda, probablemente del Pacífico Colombiano. Nieves - quién trabaja como una empleada de servicio en los años 1960 y quién se convierte en una estudiante de filosofía en la década de los 1990 - reúne todos los estereotipos que se tienen del afrodescendiente reduciéndolo a un habitante de tierras húmedas, calurosas y ejerciendo trabajos no muy bien remunerados. Las mujeres "re-presentadas" de Angulo en Negra menta y la caricatura de Nieves son personajes tomados de la realidad que nos recuerdan la carga segregacionista que porta la población afrocolombiana a pesar de los impulsos dados por la Constitución de 1991. Nieves y su arsenal imaginario "nos obligan a renunciar a toda definición unívoca e irreverente del otro y a tomar como objeto de análisis no una supuesta "identidad negra" sino los mecanismos relacionales, situacionales y parciales de atribución de estatus" (CUNIN, 2016: s.p.). 


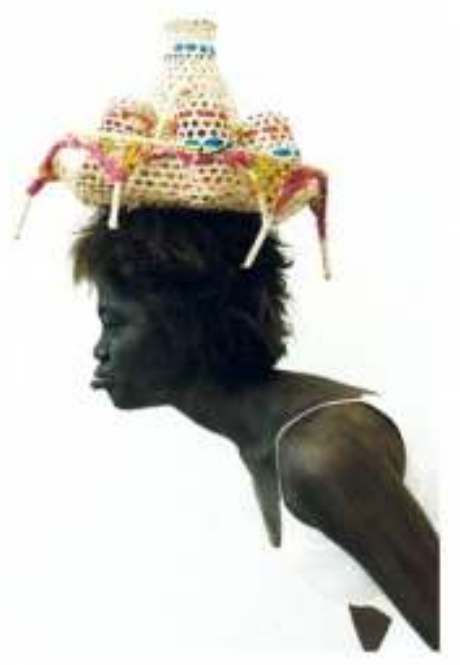

Negra menta, 2000

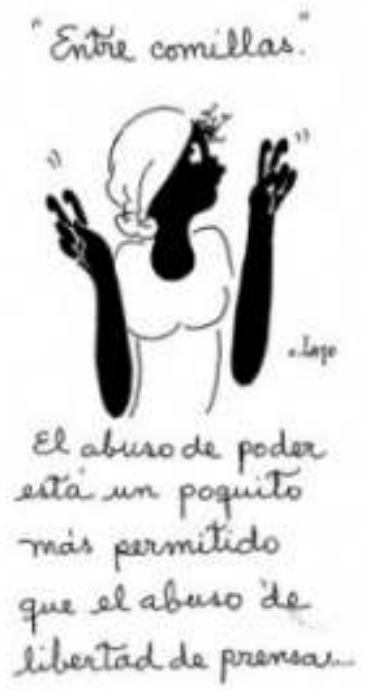

Impresión a color, 50×40 cm.

Colección Banco de la República de Colombia, Bogotá.

Para la realización de estas fotografías, Angulo se inspira de Nieves y retoma la vida cotidiana de una adolescente tumaqueña ${ }^{6}$ quién trabaja como empleada doméstica en una casa de Bogotá. Angulo recuerda a través de su obra la realidad, muchas veces invisible, de numerosas niñas migrantes que se desplazan a las grandes urbes colombianas para trabajar en el servicio doméstico (PORTILLA, 2011: s.p.). Pintando de negro el rostro y el cuerpo de la tumaqueña, Angulo insiste en la importancia de este color como característica positiva, distintiva e identitaria. Para la artista, el negro no contiene ninguna connotación peyorativa como la mirada racista lo ha hecho entender vinculándolo a ciertas imágenes de raza y de lo exótico. El color negro engloba toda una historia personal, colectiva y ancestral que la identifica con una comunidad. Reforzando el color negro en el rostro y el cuerpo de la modelo, Angulo no hace nada 
más que enfatizar su procedencia decodificando los términos opuestos de blanco/negro tan presentes en Occidente, y en Colombia. Además, plantea una propuesta visual en la que siendo fiel al formato y a los colores de la caricatura de Nieves, reduce la profundidad de la imagen fotográfica, imitando de esta manera la bidimensionalidad del papel (SHOUSE TOURINO, 2009: 239).

Vestida como Nieves y encontrándose en un espacio indeterminado de color blanco, Angulo contrapone lo que para muchos es un espacio "puro" con la "impureza" del color de piel de la modelo. La dicotomía blanco/negro es utilizada por la artista como un medio para desestabilizar lo que tradicionalmente esta jerarquizado: lo blanco como símbolo de pureza, perfección, orden, civilización, modernidad es contrapuesto con el negro que cristaliza todo lo contrario. No es gratuito que el demonio sea vinculado al color negro desde los tiempos de la Colonia. El esclavo africano encarnó para el español el "deseo malo, el retoño de emociones pulsionales rechazadas, cuyas manifestaciones son culturalmente neuróticas” (BORJA, 1997: 161). En Negra menta, Angulo problematiza jerarquías históricas y discursivas a través del duplo blanco/negro interrogándose sobre "el estatus natural de los aparentes pares dicotómicos y visibiliza su interdependencia e inestabilidad internas" (GIRALDO, 2014: 22).

Negra menta puede ser relacionada con la obra de la afroamericana Adrian Piper llamada My calling card N1 (1986-1990, Walker Art Center). La artista, cansada de los comentarios racistas, extendía su mano y entregaba una carta de presentación en la que se encontraba escrito el siguiente mensaje: "Dear Friend/I am black. / I am sure you did not realice this when you made/laughed at/agreed with that racist remark." La obra de estas dos artistas encuentra un interesante eco con el trabajo de la afroamericana Kara Walker, Insurrection! Our Tools Were Rudimentary, Yet We Pressed On (2002, Solomon R. Guggenheim Museum, New York). Proyectando largas y delicadas siluetas negras sobre fondos blancos, Walker narra la historia de una revuelta en el sur de los Estados Unidos en la que los esclavos destripan a su amo con un gran cucharón. Walker y Angulo se refieren a la esclavitud y a los objetos utilizados tradicionalmente por las empleadas domésticas afrodescendientes (cucharón, trapero, escoba, delantal, pañoleta, etc.)) con el fin de denunciar éste estereotipo y afirmar una historia particular, la de la diáspora africana. ${ }^{7}$ 


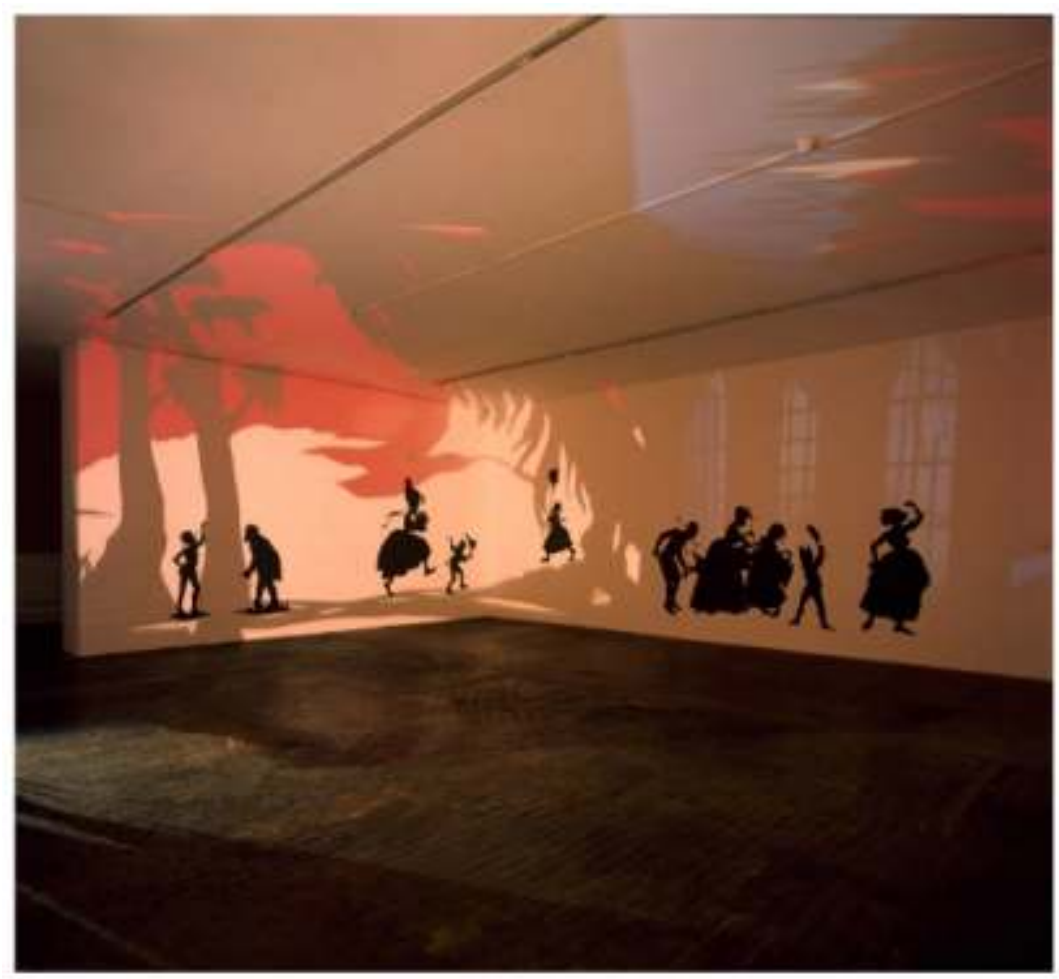

Papel y proyecciones de luz, dimensiones variables, Solomon R.

Guggenheim Museum, New York.

El performance de Piper, la instalación de Walker y las fotografías de Angulo exponen una preocupación con respecto a la autoidentificación y a la autoafirmación identitaria. Procesos que se llevan a cabo interrogando y deconstruyendo jerarquías como las de los colores. A contrapelo de las acciones mencionadas, el blanqueamiento que se impuso el cantante Michael Jackson y el uso de productos estéticos para aclarar la piel prueban el peso que tiene la sociedad occidental sobre la mirada que el afrodescendiente tiene de sí mismo. Para aquellas personas, el blanqueado de piel es un proceso esencial para sertirse atractiva/o y aceptada/o. Además de convertirse en un fénomeno popular, el blanqueamiento de piel expone sobretodo "un complejo de negro, que pasó de ser motivo de orgullo en los años 1960, a motivo de vergüenza en la actualidad" (VARGAS, 2004: s.p). Mientras que las artistas sienten la necesidad de una doble autoafirmación (la de ser mujeres y ser afrodescendientes), para Jackson y los otros es la negación de su origen. Estos ejemplos muestran cómo la dicotomía blanco/negro y las categorías de género y de clase se encuentran interrelacionadas e inscritas en los cuerpos y en el imaginario colectivo de las comunidades que construyen à partir de éste último sus relatos individuales y nacionales.

Dentro de esta comunidad imaginada que es la Nación Colombiana (ANDERSON, 1993: 23-25) ${ }^{8}$ se encuentra actualmente expresiones populares que resuenan con la propuesta de autoafirmación que desarrolló Angulo en Negra menta. Gracias a las dinámicas jurídicas originadas por la Constitución de 1991, el Pacífico Colombiano conoció un "régimen enteramente nuevo de la identidad" que fue formulado, según Escobar, en términos de etnicidad y del concepto de comunidades negras. Antes de la Constitución existía una incapacidad de articular los intereses de las comunidades 
negras del Pacífico, después de 1991 hubo una "ruptura que significó la reubicación de lo negro en el imaginario cultural y político de la nación junto con una nueva política de la representación." Para ello, fue fundamental el artículo transitorio 55 y la Ley 70 de 1993 que promovieron prácticas institucionales como la creación de la Comisión Especial para las Comunidades Negras y de nuevas organizaciones sin ánimo de lucro (ESCOBAR, 2010: 241). Los afrocolombianos pasaron entonces de ser invisibles a ser protagonistas de una historia y cultura nacional que les había ignorado, maltratado y despreciado desde la colonización.

Las nuevas dinámicas sociales ofrecidas por la Constitución de 1991 dieron origen a expresiones artísticas como la de Angulo o como la de ChocQuibTown, grupo de Hip Hop que promueve, a través de la mezcla de la música electrónica, el funk y el reggae, los ritmos tradicionales del Pacífico Colombiano como el currulao, el bambazú y el aguabajo. Creado en el año 2000, ChocQuibTown lanza en el 2006 el sencillo Somos Pacífico que se convierte en un éxito nacional gracias al carácter apologético de su letra:

Somos Pacífico, estamos unidos, Nos une la región. La pinta, la raza y el don del sabor. Es toda una conexión. Con un corrillo Chocó, Valle, Cauca. Y mis paisanos de Nariño. Todo este repertorio me produce orgullo. Y sí somos tantos. Porque estamos tan al cucho (* en la esquina). Unidos por siempre, por la sangre, el color. Y hasta por la tierra. No hay quien se me pierda. Con un vínculo familiar que aterra. Característico en muchos de nosotros. Que nos reconozcan por la mamá....

Tanto Negra menta como Somos Pacífico redescubren la identidad afrocolombiana a través de diversos elementos como el color negro, la procedencia regional, la historia común de la diáspora, la cultura y el papel cohesionador del sujeto femenino. El "redescubrimiento" del elemento negro realizado por el Estado en 1991, y tiempo después dentro de las mismas comunidades del Pacífico Colombiano, permitió en consecuencia su reconocimiento dentro del campo del arte nacional como lo testimonia la exposición Viaje sin mapa. Partiendo de la pregunta de Raúl Cristancho sobre el porqué de la inexistencia de la presencia de artistas afrocolombianos en el panorama nacional, se realizó en 2004 el proyecto Viaje sin mapa que reunía la obra de diferentes artistas contemporáneos de color dentro de los cuales encontramos el trabajo de Angulo. Si bien es cierto que la música, la danza y las tradiciones orales han sido reconocidas como parte integral de la cultura nacional - dentro de su componente folklórico - las expresiones artísticas afrocolombianas (pintura, escultura, performance, instalación, video, etc.) han sido excluidas del imaginario nacional (CRISTANCHO, 2006: 11-12). Es por esto que el trabajo de Angulo es tan importante puesto que se inserta y destabiliza desde el interior las jerarquías del arte.

\section{Una imagen heredada de la mujer afrocolombiana}

23 Si las mujeres afrocolombianas se encontraban organizadas alrededor de actividades comunitarias y cotidianas desde hacía mucho tiempo, después de la promulgación de la Constitución de 1991 tales organizaciones se institucionalizaron gracias al apoyo financiero estatal e internacional. Por primera vez, las comunidades negras y sobre todo sus mujeres hicieron parte de proyectos estatales que estuvieron mediados, sin embargo, por múltiples negociaciones y objeciones (ALVAREZ, 2012: 280). La preocupación por hacer visible la mujer afrocolombiana recorrió igualmente la obra de Angulo desde sus estudios de pregrado en la Universidad Nacional de Colombia. Reconociendo primero su origen negro, Angulo se interesó tiempo después en la 
manera cómo la mujer afrocolombiana era pensada, imaginada, mirada y representada. A lo largo de su obra, Angulo cuestiona las implicaciones de lo que es ser una mujer afrodescendiente en Colombia donde la inequidad de género, la violencia, la pobreza, el desplazamiento forzado y el racismo están cotidianamente presentes.

Sin tener en cuenta los contextos socio-políticos, simplificando y naturalizando las características de una identidad y otorgándole atributos negativos, los estereotipos han reducido a las mujeres afrocolombianas a objetos hipersexuales o a sujetos de segunda categoría. Nieves y la tumaqueña fotografiada por Angulo sosteniendo un trapero y una escoba, encarnan perfectamente la idea que se tiene de la mujer afrocolombiana: un sujeto doblemente subalterno por su origen y por su trabajo como empleadas de servicio. Además, sus cabellos rizados, el uso de vestido blanco, sus miradas nostálgicas y su posición de expectantes hacen referencia a los rasgos físicos y psicológicos que son otorgados a los afrocolombianos: personas simples, de buen humor, amables e inocentes con nariz chata y boca abultada (GIRALDO, 2014: 71). En una de las fotografías de la serie Negra menta, la modelo está degustando la sopa con un gran cucharón de metal haciendo referencia a esas grandes matronas negras que, desde la Colonia, ayudan a criar a los herederos blancos. Ésta fotografía resuena con la famosa obra de Betye Saar The Liberation of Aunt Jemima de 1972, en donde observamos una enorme replica sonriente de Aunt Jemima dentro de la cual se encuentra un imagen de la misma sosteniendo un bebé blanco en un jardín. Sobre un fondo que presenta imágenes publicitarias del personaje, a la manera de Warhol con sus Marilyns, la gran réplica de Aunt Jemima porta en su brazo derecho una escoba y en el izquierdo un fusil, transformando de esta manera a la feliz sirvienta en una mujer militante del black power (GIRALDO, 2014: 121).

Negra menta (versión cucharón y escoba), 2000
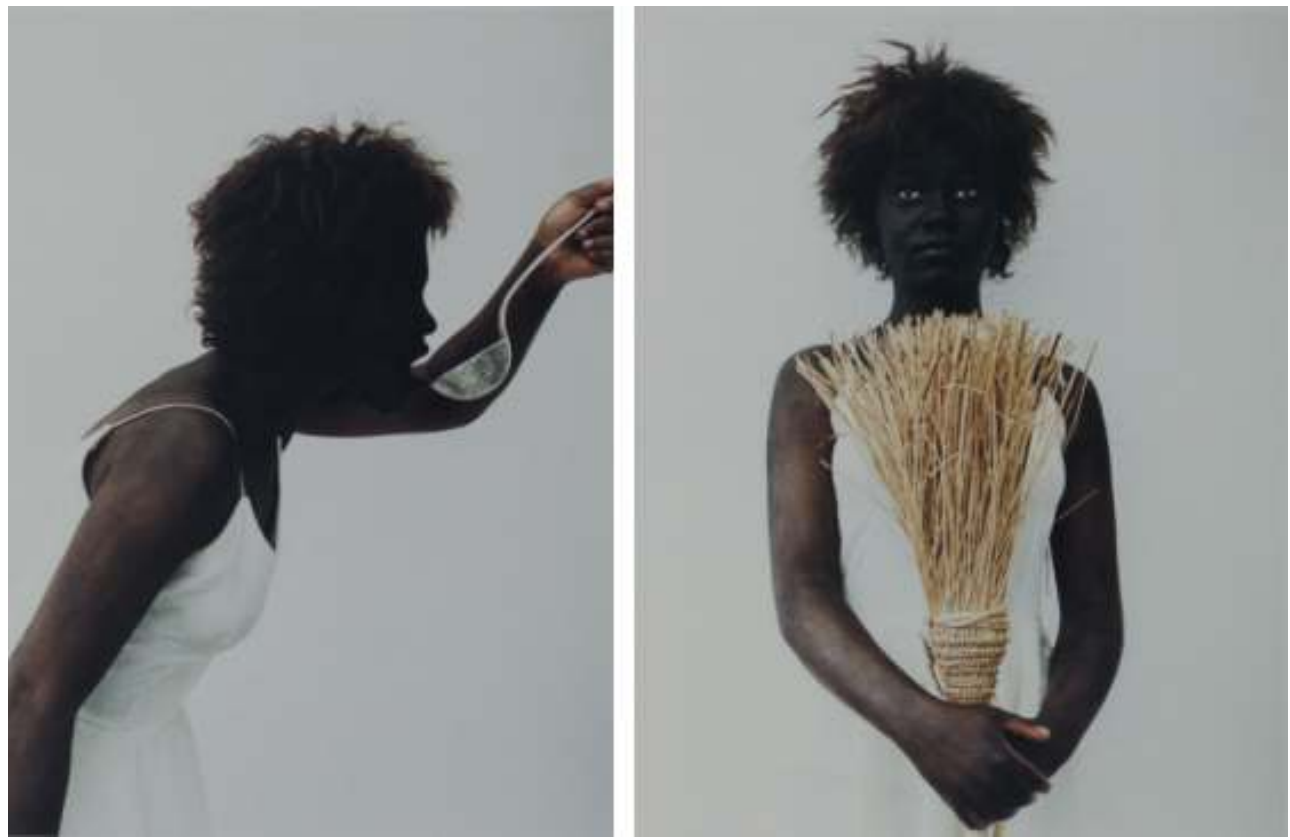

Impresión a color, $50 \times 40 \mathrm{~cm}$.

Colección Banco de la República de Colombia, Bogotá. 
tras que The Liberation of Aunt Jemima se refiere a una situación de conmoción en los Estados Unidos relacionada con la lucha de los derechos civiles de las afroamericanos, Negra menta (versión cucharón y escoba) denuncia la creencia social de que el destino de las afrocolombianas es ser empleadas de servicio. Su obra provoca un dialogo ético con el público puesto que lo hace reflexionar, a través de los objetos como escobas, traperos, cucharón, etc., el lugar de la mujer afrocolombiana dentro de la constitución del imaginario nacional. Con esto me refiero a que Angulo desfamiliariza al púbico de los estereotipos subterráneos y lo aleja de los imaginarios de pobreza, ignorancia, subordinación que constituyen la mirada mestiza y blanca sobre el afrocolombiano. Angulo resalta igualmente la importancia del papel de las empleadas de servicio afrocolombianas en la constitución de la sociedad colombiana. Siendo un trabajo "invisible, repetitivo, improductivo" (DAVIS, 2005: 221), Angulo crea una nueva conciencia frente a esta actividad que es una realidad diaria para muchas mujeres de color.

En otra de las fotografías de Negra menta, la modelo con mirada nostálgica se encuentra sentada sobre una butaca, portando dos rulos de color azul sobre su cabello rizado y en su mano izquierda un cepillo. Ésta obra hace referencia a la importancia del cabello para las afrodescendientes quienes, en su gran mayoría, gastan una enorme cantidad de dinero para tenerlo liso, sedoso y brillante según los cánones de belleza occidental. Ellas se han visto obligadas a hacer concesiones en su cuerpo y en su cabello para encajar en el canon tradicional. Chris Rock en su documental Good Hair (2009) se concentra en mostrar lo que es una cabellera negra aceptable y deseable. Además, explora las diferentes técnicas que las afroamericanas adoptan para alisar sus cabellos y mantenerlo en ese estado a pesar de su naturaleza rizada.

Negra menta (versión rulos), 2000

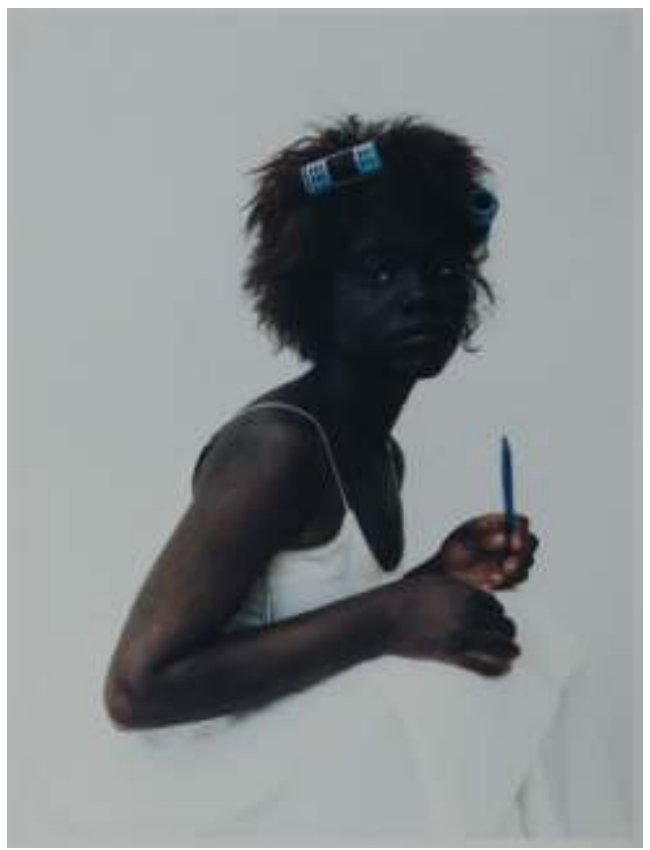

Impresión a color, 50x40 cm.

Colección Banco de la República de Colombia, Bogotá. 


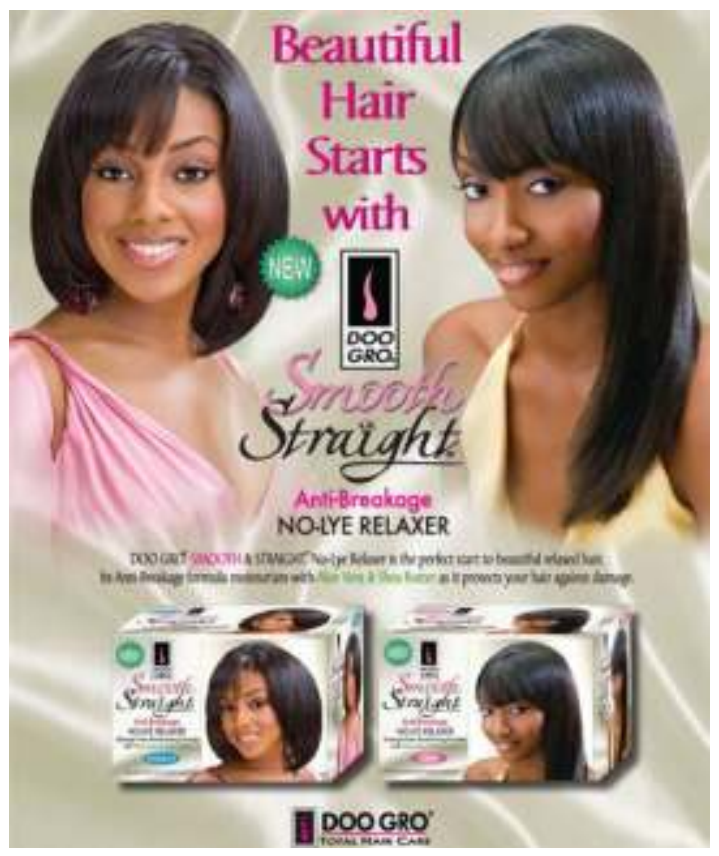

La fotografía de Angulo (versión rulos) y la película de Rock dialogan con la obra de Lorna Simpson, Stereo Styles de 1988, en donde la afroamericana muestra las diez maneras posibles de peinar un cabello rizado sin mostrar el rostro de la mujer. Utilizando flores, cintas, hebillas, cauchos, etc., y acompañando cada estilo con adjetivos calificativos como Daring, Sensible, Severe, Ageless, Silly, Magnetic, entre otros, Simpson invita al espectador a realizar diferentes conexiones entre imagen y texto. Tanto las fotografías de Angulo como las de Simpson critican el postulado de que el peinado define la identidad de una persona. El rostro nostálgico de la modelo de Angulo y el cambio constante de peinado que presenta Simpson reflejan el estado inestable y la soledad por el cual numerosas afrodescendientes pasan por sentirse avergonzadas de su cabello rizado (BELISLE, 2011: 160-161). La misma Angulo declara: "mi acto de afirmación al llegar a la adultez fue liberar el pelo, usarlo suelto o con peinado afro. Peinados afro considerados feos. Luego me calvée yo misma a los 20 años pero eso fue una acto más de rebeldía en protesta contra la supuesta feminidad" (GIRALDO, 2014: 161).

Dentro de la serie Negra menta, se observa otra fotografía en la que la modelo sentada sostiene y mira directamente la cabeza de un maniquí. Aquí Angulo declara no sólo su posición estética sino ética que asumirá plenamente en sus obras posteriores. La modelo observa atentamente la cabeza blanca de un maniquí - paradigma de la belleza occidental - dándose cuenta que no cumple con las proporciones y exigencias corporales dictadas por Occidente (GIRALDO, 2014: 63). Su color de piel, la forma de su cara, su nariz, sus ojos, su cabello no encajan ni empatan con las medidas y características del maniquí. Sin embargo, en Negra menta y en especial en ésta fotografía, la afrocolombiana se convierte en sujeto, ya que es ella quién recupera la mirada del espectador. La cabeza del maniquí, simbolizando la mujer blanca, es sólo un objeto más que desaparece con el fondo blanco de la fotografía. 
Negra menta (versión maniquí), 2000

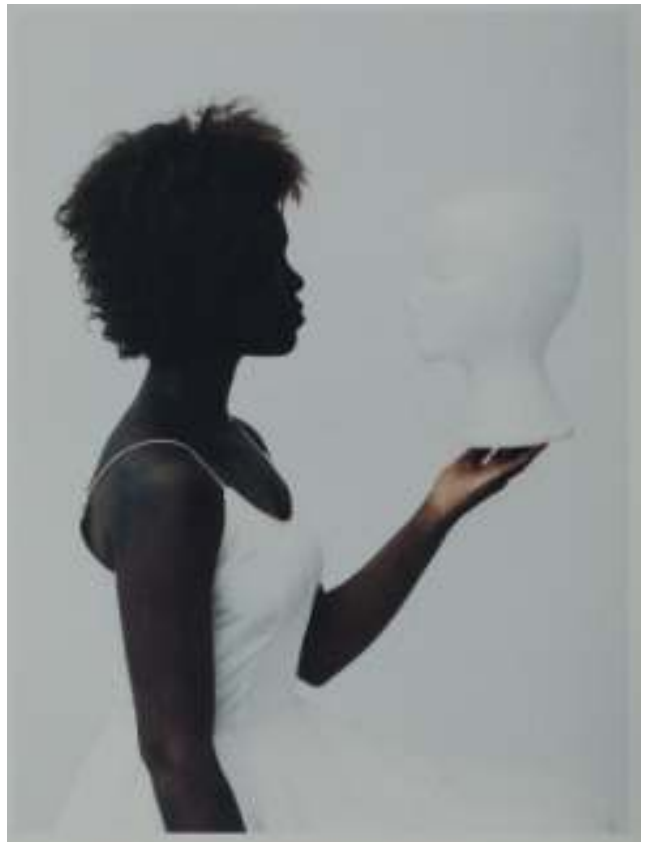

Impresión a color, 50x40 cm.

Colección Banco de la República de Colombia, Bogotá.

Carrie Mae Weems, Mirror Mirror, 1986

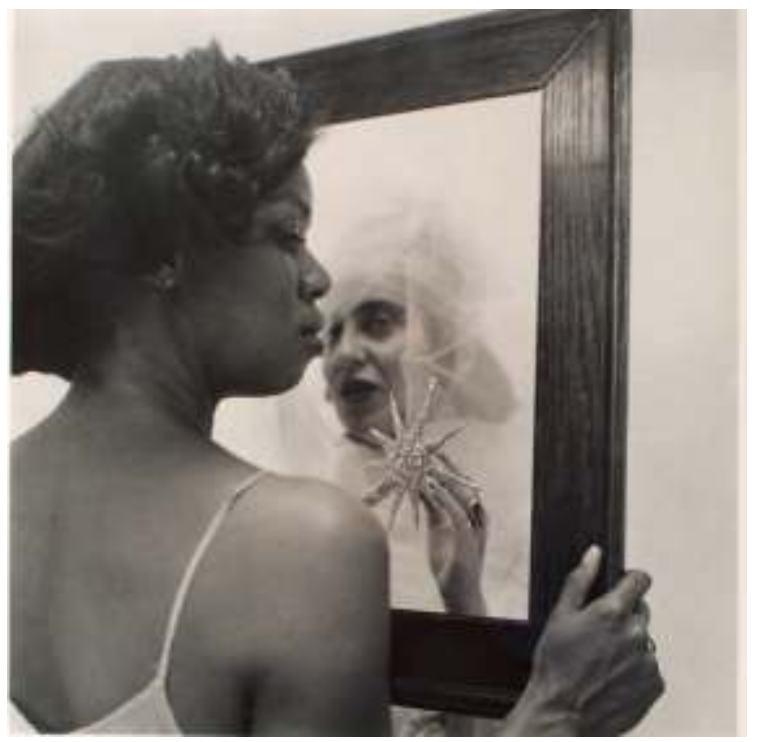

Looking into the mirror, the black woman asked,"Mirror, mirror on the wall, who's the finest of them all?". The mirror says,"Snow white, you black bitch, and don't forget it!!!".

Impresión a color, 36.8 × $36.2 \mathrm{~cm}$. International Center of Photograph, New York.

International Center of Photograph, New York.

Negra menta (versión maniquí) hace eco con el trabajo de Carrie Mae Weems, Mirror Mirror (1986, International Center of Photograph), en el que la artista frente a un espejo pregunta: "mirror, who's the finest of them all? The mirror says, "Snow White, you black bitch, and don't you forget it !" A través de la mirada, las dos artistas cuestionan el sistema opresivo que autoriza y mantiene los cánones y valores de belleza occidentales. Más allá 
de criticar la mediatización de la mirada, ellas sitúan en el centro la visión que la mujer afrodescendiente tiene de ella misma y de cómo han sido vistas a lo largo del tiempo. Históricamente, las mujeres de color han sido encasilladas como buenas cocineras, ardientes amantes y excelentes bailarinas (LOZANO Y PEÑARANDA, 2007: 717). Desde una mirada erotizante y exotizante, ellas hacen parte del paisaje colombiano como palenqueras ${ }^{9}$, vendedoras de frutas como lo ejemplifican las obras de Ana María Hoyos y de Enrique Grau.

Dos de las fotografías de la serie Negra menta hacen referencia a la trata de esclavos. La primera muestra a la modelo sosteniendo una reja y en la segunda se observa a la misma mujer encadenada con grilletes de hierro en el cuello y manos. En las dos fotografías, la mirada perdida y la posición impávida nos transportan al infierno que los esclavos tuvieron que vivir durante la trata. Las fotografías de Angulo adquieren aquí un carácter histórico puesto que se interroga sobre el papel del negro en la construcción de la nación colombiana.

Negra menta (versión reja y grilletes), 2000
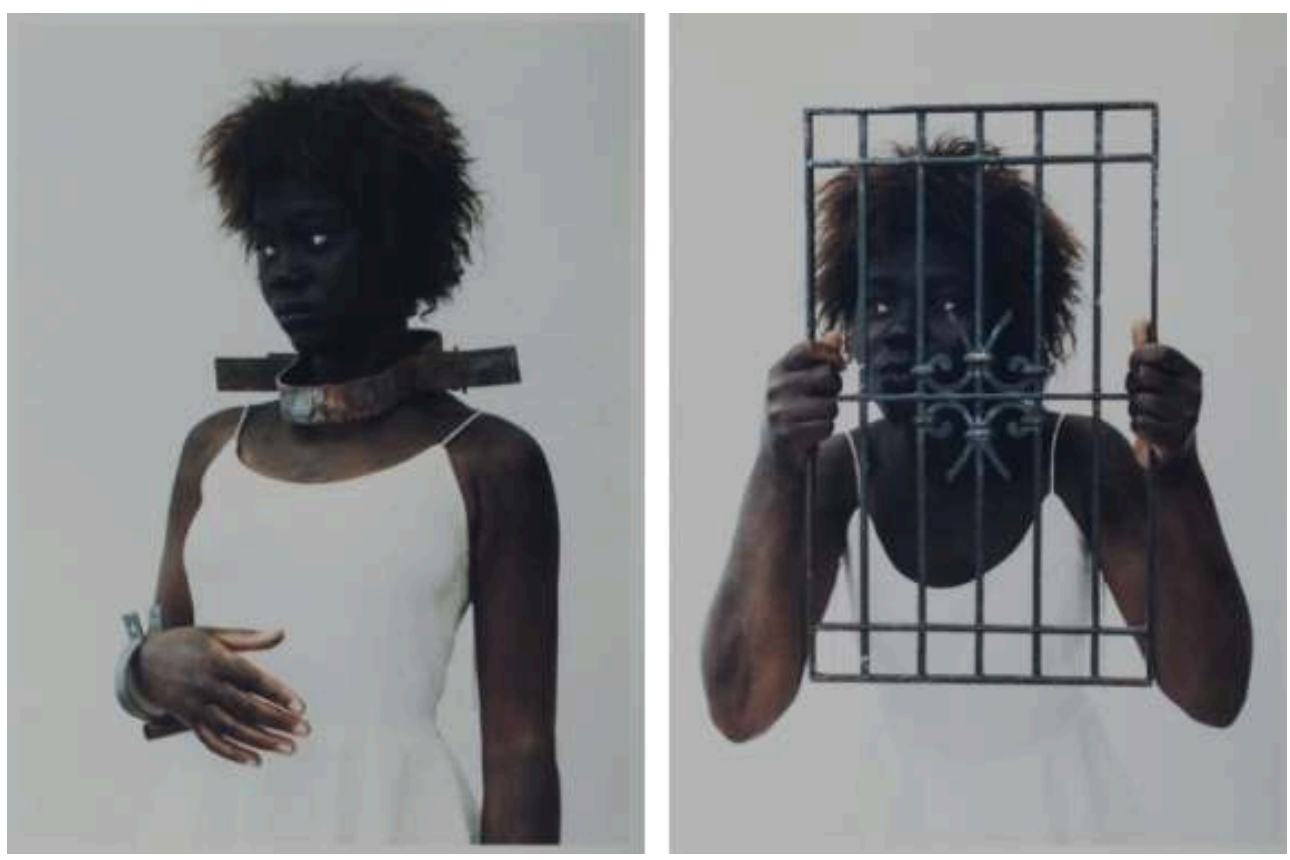

Impresión a color, 50 × 40 cm.

Colección Banco de la República de Colombia, Bogotá.

31 A diferencia de los indígenas, los africanos fueron considerados por los españoles como objetos sin valor humano y las mujeres como no-seres capaces de trabajar como los animales (GIRALDO, 2014: 55). El trabajo de Angulo se dirige a resaltar el lugar de la mujer afrodescendiente en la historia nacional. Ella se pregunta por la manera más efectiva de combatir el sexismo y el racismo, fenómenos sociales que impiden reconocer la participación de las afrocolombianas en la construcción del país. La nación colombiana se cimentó, desde sus albores coloniales, bajo un sistema de distinciones y jerarquías de identidades articuladas en función del color de la piel y de la pureza de sangre. A diferencia del feminismo europeo y norteamericano que se basó en la afirmación de Simon de Beauvoir "no se nace mujer, se llega a serlo", las feministas afrodescendientes tuvieron que partir de una negación: no ser mujer (JABARDO, 2012: 
29). En 1851, la afroamericana Sojourner Truth pugna en su famoso texto Ain't I a Woman?, la creencia de que las mujeres de color no son mujeres. Ella luchó por resignificar el término de mujer negra en su aspiración de ser libre tanto de la dominación sexista como racista. Esta lucha resuena con las dos fotografías de Angulo que retoman precisamente esa negación para establecer una protesta visual en la que se afirma la participación activa de la mujer africana en la edificación de la historia colombiana.

En una entrevista Angulo declara que "la identidad negra ha sido negada durante tanto tiempo por las élites que ahora se alimenta de lo que aparezca" (SHOUSE TOURINO, 2009: 228). Esta citación, que recuerda los postulados modernistas de Oswald de Andrade en su Manifiesto Antropófago de 1922, expone la necesidad de recuperar las tradiciones étnicas y culturales negras devorando lo impuesto por los blancos. Negra menta invierte la relación colonizador/colonizado haciendo que su modelo utilice un vestido blanco y se convierta en sujeto de la obra. Además, recurriendo a la fotografía, que fue un dispositivo utilizado para documentar la vida de los "Otros" desde una perspectiva científica, Angulo se apropia de este medio y digiere las imágenes capturadas por los antropólogos y etnógrafos de comienzos de siglo XX. La fotografía es utilizada para destruir el imaginario colonial que atraviesa la historia de las comunidades afrocolombianas (GIRALDO, 2014: 81). Angulo vuelve visible lo invisible alterando los usos que tenía la fotografía etnográfica.

Para terminar este análisis iconográfico, se toman dos de las deciocho fotografías de Negra menta. En una de ellas se observa a la modelo portando una pistola con mirada desafiante al estilo James Bond. En la otra, ella se encuentra de frente con casco y pala de minero. Las dos fotografías reenvían a dos clases diferentes de violencia. Mientras que en la primera la modelo parece defenderse de un ataque, en la segunda ella está obligada, por las circunstancias de pobreza y miseria, a trabajar como minera bajo condiciones infrahumanas. La idea del esclavo sumiso e inocente es subvertida por Angulo quien apodera a la mujer afrocolombiana con un arma (GIRALDO, 2014: 95). En el caso de la minera, la mujer es violentada por el escenario en el que ella se encuentra. Alrededor de las minas numerosas familias afrocolombianas se han ido constituyendo desde los tiempos de la Colonia. Sin embargo, la situación de violencia del país ha hecho que estas familias se dispersen y que las tradiciones ancestrales fundadas en el papel central de la mujer y en la actividad minera se pierdan. (FRIEDEMANN y ESPINOSA, 1998: s.p.). 
Negra menta (versión James Bond y minera), 2000.
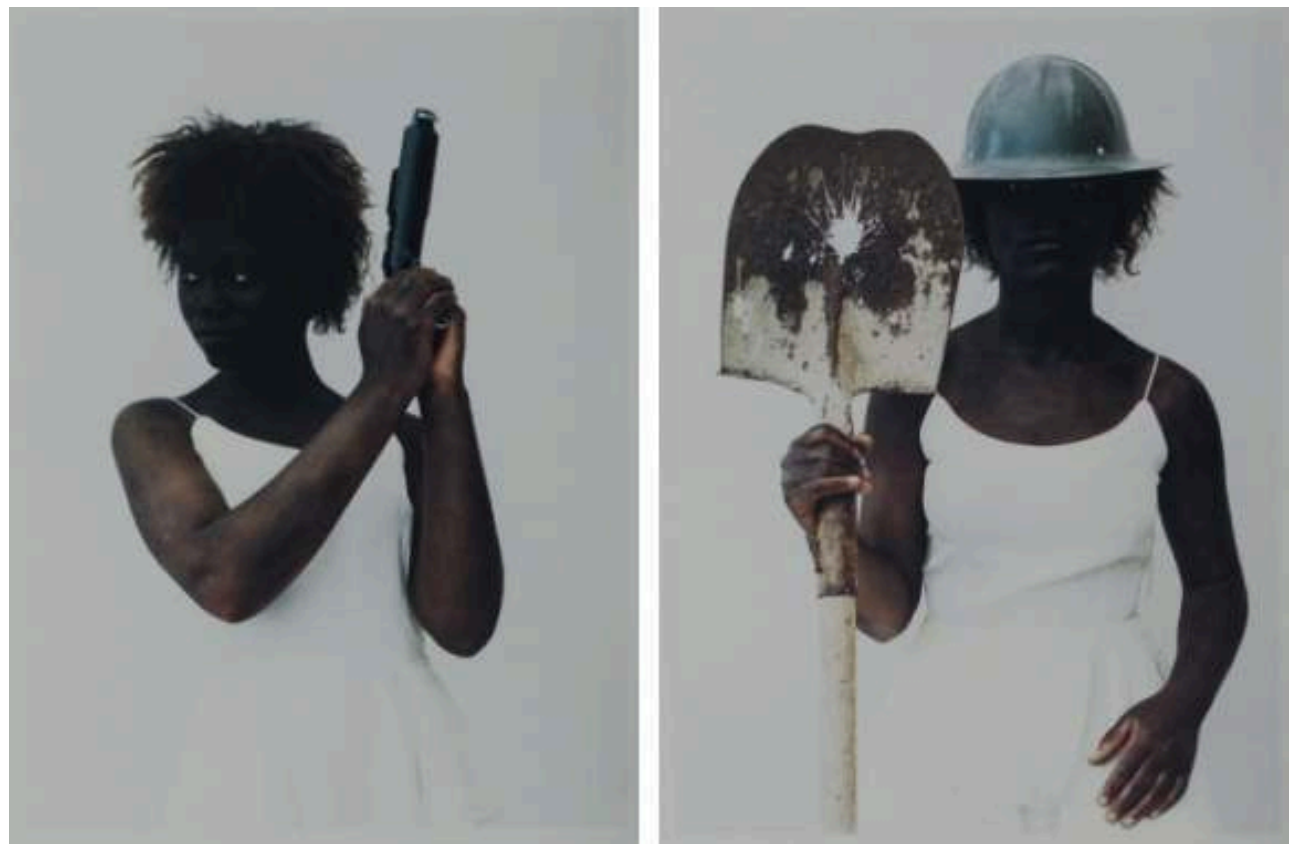

Impresión a color, $50 \times 40 \mathrm{~cm}$.

Colección Banco de la República de Colombia, Bogotá.

La minería en el litoral del Pacífico fue una actividad realizada por los indígenas con connotaciones rituales y simbólicas bien antes de la colonización. Lo que cambia cuando arriban los europeos son las condiciones de trabajo, la producción y el incremento de la actividad. El impacto ambiental y el deterioro humano que causa la sistematización de la extracción aurífera no han cambiado desde la Colonia, al contrario, Colombia se caracteriza por ser uno de los países con una importante actividad minera ilegal (MANGA, 2015: s.p. / RODRIGUEZ, 2011: s.p.). Mientras que en la colonia los esclavos eran obligados a trabajar, en la actualidad los afrodescendientes trabajan para sobrevivir, dos diferentes tipos de violencia. La ausencia de asistencia técnica, el abandono estatal y la presencia de grupos armados, han generado la degradación sistemática de los recursos naturales, el desplazamiento de varias familias y la creación de focos de miseria (GONZALEZ, 2003: s.p.). Las dos fotografías de Angulo despliegan la contradicción en la que las afrocolombianas son forzadas a vivir. Protegiéndose con armas y subsistiendo con las palas, las mujeres afrocolombianas siguen siendo invisibles, y lo que es lamentable, es reconocer que aquella invisibilidad parte, muchas veces, desde el interior de las comunidades negras en donde el hombre violenta y ataca a las mujeres (LOZANO Y PEÑARANDA, 2007: 722).

En conclusión, la obra de Angulo es pionera dentro del contexto artístico nacional primero porque ejerce un proceso de autoafirmación en el que la deconstrucción de códigos sociales se realiza a través de la dicotomía blanco/negro. Es decir, que opera una actitud transgresora desde los mismos presupuestos modernos del arte: la mujer negra ya no es objeto de representación ni de estudio, ella se convierte en sujeto activo. Segundo, porque hace parte de este grupo de artistas afrocolombianos que buscan un lugar dentro del sistema blanco de las artes plásticas reivindicando su origen y su cultura. Tercero, porque siendo mujer de color retoma los clichés y los estereotipos 
atribuidos a la mujer afrodescendiente para desestabilizar el sistema patriarcal y sexista que rige la sociedad colombiana.

Partiendo de una sola obra, Negra menta, vimos la manera cómo Liliana Angulo deconstruye los presupuestos racistas y cuestiona los estereotipos asociados a la mujer afrodescendiente. Utilizando la fotografía, Angulo muestra, a partir de la caricatura de Nieves y de la vida de la modelo tumaqueña, la historia de las mujeres afrocolombianas desde los tiempos de la Colonia hasta la actualidad. Ésta obra rastrea la construcción del imaginario colectivo sobre lo afrocolombiano teniendo como contexto el marco jurídico, político y social ofrecido por la Constitución de Colombia de 1991. Reconociendo que hubo ciertos adelantos con respecto a los derechos civiles de los afrocolombianos, el cuestionamiento que propone Angulo con Negra menta, expone ciertas contradicciones que la nueva Constitución no ha podido resolver puesto que el imaginario colectivo aún no ha aceptado el elemento negro dentro del componente nacional. Los cambios que introdujo la Constitución fueron radicales ya que el Estado aceptó proteger la diversidad étnica y cultural de la nación, además de garantizar los derechos específicos de las comunidades negras. Sin embargo, como lo menciona Jaime Arocha, en Colombia "se ha desarrollado una especie de consenso nacional en torno al posible valor terapéutico del silencio racial. O que ese silencio contribuyera a salvaguardar la idea de que el mestizaje es una fuerza democratizante, mito que fue ampliado en la década de 1980" (AROCHA, 1998: s.p.).

Luchando contra este "silencio terapéutico" y contra la doble subordinación a la que la mujer afrocolombiana se encuentra sometida, Angulo propone con su Negra menta las siguientes preguntas: ¿Cómo terminar con el racismo y el sexismo que afecta cotidianamente la vida de la mujer de color? ¿De qué manera se podría reparar a las comunidades negras del ostracismo al que han sido obligadas a vivir desde la Colonia? ¿Quién podría responder por los daños causados por la destrucción de millones de hectáreas de bosque húmedo en el Pacífico Colombiano y del desarraigo cultural del que están siendo víctimas a causa de la violencia? ¿De qué manera incluir la cultura afro dentro de un país que se considerada mestizo e incluso blanco? Lo que permitió la Constitución de 1991 fue el "re-descubrimiento" de lo negro en el panorama nacional, y tiempo después, en el campo artístico. Se aceptó entonces el carácter histórico de las identidades negras y fue precisamente este elemento el punto de partida de la obra de Angulo. Reflexionando sobre sus orígenes, la artista realizó su obra Negra menta en la que buscó afirmar su identidad afrocolombiana. Entendiendo la identidad "como una forma compleja del entendimiento de sí mismo e improvisada a partir de los recursos culturales a mano en un contexto histórico particular" (ESCOBAR, 2010: 246), Angulo hace uso de la caricatura de Nieves y de la vida de la tumaqueña para relacionar sus vivencias personales con la colectividad afrodescendiente.

Negra menta se constituye en un ejercicio de autoafirmación en la que Angulo interroga las creencias populares según las cuales la mujer afrodescendiente es por un lado atrasada, salvaje, ignorante, pobre e inculta, y por el otro, ardiente, sensual y provocativa. Contraponiendo estos adjetivos sobre la imagen de una caricatura recreada por una verdadera afrocolombiana, Angulo hace que el espectador reflexione sobre la manera cómo las dicotomías - esclavo/libre, mujer/hombre, mujer blanca/ mujer negra - sean "expresiones de una geografía imaginaria de relaciones de poder neocoloniales. Relaciones que son fragmentos de ideologías hegemónicas dispersas que desde tiempo atrás han colonizado las mentes hasta de los más puros de nuestros 
sujetos antropológicos" (ALVAREZ, 2012: 274). Las preguntas que se hace Angulo a través de Negra menta cristalizan la preocupación de varios artistas contemporáneos de relacionar la ética artística con la política. Realizando talleres con comunidades afrocolombianas y con colectivos de mujeres de color, Angulo parte de lo visual para hacernos interrogar sobre las maneras en que los estereotipos femeninos operan dentro de las mismas comunidades negras y nos invita a observar cómo éstos crean complejos personales que afectan finalmente el registro colectivo (APONTE, 2009: s.p.). En el caso colombiano, esos complejos son doblemente pesados puesto que el contexto de violencia y de pobreza refuerza aún más su condición de subalternos.

\section{BIBLIOGRAFÍA}

ALVAREZ Manuela (2012). “Capitalizando a las mujeres negras: la feminización del desarrollo en el Pacífico Colombiano” en Eduardo RESTREPO y María Victoria URIBE (Comp), Antropologías transeúntes, Instituto Colombiano de Antropología e Historia, Bogotá, Colombia, pp. 269-288. ANDERSON Benedict (1993). Comunidades imaginadas, Fondo de Cultura Económica, Ciudad de México.

ANZALDUA Gloria (1987). Crossing Borders: The new Mestiza, Aunt Lute Book, San Francisco, Estados Unidos.

APONTE Mila (2009). Entrevista a Liliana Angulo durante el 7 mo Encuentro del Instituto Hemisférico de Performance y Política, 2009 en Bogotá, “Ciudadanías en escena: entradas y salidas de los derechos culturales". [en línea http://hidvl.nyu.edu/video/00347502.... Consultado el 25 de marzo 2016]

APPADURAI Arjun (2010). "How Histories make Geographies. Cicrulation and Context in a Global Perspective". Transcultural Studies, University of Heidelberg, Alemania, No 1, 2010, pp. 4-13. [DOI: http://dx.doi.org/10.11588/ts.2010.1.6129. Consultado el 20 Marzo 2016]

AROCHA Jaime (1998). “La inclusión de los Afrocolombianos. Meta inalcanzable?”. Geografía Humana de Colombia: Los Afrocolombianos. Tomo VI, 1998, Biblioteca Virtual Luis Angel Arango. [http:// www.banrepcultural.org/blaav... Consultado el 20 Marzo 2016]

BELISLE Brooke (2011). “Felt Surface, Visible Image: Lorna Simpson's Photography and the Embodiment of Appearance". Photography and Culture, Vol 4, No 2, Julio, pp. 157-178.

BOJAYA, (2010). La guerra sin límite. Informe del Grupo de Memoria Histórica de la Comisión Nacional de Reparación y Reconstrucción, éd. Taurus, Bogotá, Colombia, pp. 35-80.

BORJA Jaime Humberto (1997). “Demonio y nuevas redes simbólicas: Blancos y negros en Cartagena, 1550-1650", en GARCÍA AYLUARDO Clara y RAMOS Medina. Manuel, Manifestaciones religiosas en el mundo colonial americano, Universidad Iberoamericana, México, pp. 147-167. BOTERo Chica, CARLos Alberto (2010). 'El Choco biogeográfico un tesoro de la naturaleza'. Colombia Revista Ciudad, de Asuntos Urbanos, V.5 N.17, p. 8 - 14, [en linea EcoPortal. Net, http:// www.ecoportal.net/TemasEspec.... Consultado el 22 de marzo de 2016] 
CONSTITUTION POLITICA DE COLOMBIA DE 1991 (2010), CENDOJ, Bogotá, Colombia.

CRISTANCHO Raúl, ANGOLA Mercedes (2006). Viaje sin mapa: Representaciones afro en el arte colombiano contemporáneo, Banco de la República de Colombia, Bogotá.

CUNIN Elisabeth (2003). “La 'negra nieves' ou le racisme à fleur de peau. Regards croisés sur une caricature”. Bulletin de l'Institut français d'études andines, 32 (2) | 2003, [En línea, publicado el 08 mayo 2003, URL: http://bifea.revues.org/6164 ; DOI: 10.4000/bifea.6164. Consultado el 29 marzo 2016]

CURIEL Ochy (2002). “Identidades esencialistas o construcción de identidades políticas: El dilema de las feministas negras”. Otras Miradas, Mérida, Venezuela, V.2, N.2, pp. 96-113. [En línea http:// www.redalyc.org/articulo.oa?...> ISSN 1317-5904. Consultado el 25 de marzo de 2016]

DAVIS Angela (2005). Mujeres, raza y clase, Ediciones Akal, Madrid, pp. 221-239.

DE FRIEDEMANN, ESPINOSA ARANGo Mónica (1998). "La familia minera". Colombia Pacífico, Tomo II, s.p. [En línea http://www.banrepcultural.org/blaav.... Biblioteca Virtual Luis Ángel Arango, Consultado el 24 de Marzo 2016]

ESCOBAR Arturo (2010). Territorios de diferencia: lugar, movimiento, vida, redes. Envión Editores, Popayán, Colombia.

GIRALDo Escobar, Sol Astrid (2014). Retrato en Blanco y Afro, Colección Artistas Colombianos, Ministerio de Cultura de Colombia, Bogotá.

GONZALEZ PERAFAN Leonardo (2003). Impacto de la minería de hecho en Colombia. Estudios de caso: Quibdó, Istmina, Timbiquí, López de Micay, Guapi, El Charco y Santa Bárbara, Instituto de Estudios para el Desarrollo y la Paz, Universidad Industrial de Santader, s.p. [En Línea https://www.uis.edu.co/ webUIS/es/ca..., Consultado el 24 de Marzo de 2016]

GOMEZ CORREAL Diana Marcela (2011). Dinámicas del movimiento feminista bogotano. Historias de cuarto, salón y calle. Historias de Vida, Universidad Nacional de Colombia, Bogotá.

JABARDO Mercedes (2012). Feminismo negros, Ed. Traficantes de sueños, Madrid, España.

JARAMILlO Carmen María (2015). Mujeres entre líineas. Una historia en clave de educación, arte y género. Ministerio de Cultura de Colombia, Museo Nacional de Colombia, Bogotá.

LOZANO Betty Ruth y Peñaranda. Bibiana (2007). "Memoria y Reparación ¿y de ser mujeres negras qué?", en Claudia MOSQUERA Rosero y Luis Claudio BARCELOS, Afro-reparaciones: Memorias de la Esclavitud y Justica Reparativa para negros, afrocolombianos y raizales, Universidad Nacional de Colombia, pp. 715-727.

MARTINEZ HERNANDEZ Santiago (2014). "Historia de una "casa de pique. El Espectador, Bogotá, Colombia, 11 octubre, s.p.

MANGA Germán (2015). “El horror y la sangre del oro en el Chocó”. Semana, Bogotá, Colombia, 12 julio, s.p.

MORRIS DE FLOREZ Athala (1968). “Ama de casa crea nuevo personaje: la negrita Nieves”. El Espectador, Bogotá, Colombia, 16 octubre 1968, p.11.

Nochlin Linda (1973). “Why Have There Been No Great Women Artists?”, En Art and Sexual Politics: Why Have There Been No Great Women Artists?, Ed. Thomas B. Hess and Elizabeth C. Baker, Macmillan, New York, 1973, pp. 30-37. Este texto se encuentra también en Karen Cordero e Inda Sáenz, Crítica Feminista en Teoría e Historia del Arte, Universidad Iberoamericana: México, 2007, pp. 17-45. 
POLLOCK Griselda (1988). Vision and Difference: femininity, feminism and histories of art, Editorial Routledge, Londres, Inglaterra.

PORTILLA Isabella (2011). “La visión de la belleza”. El Espectador, Bogotá, Colombia, Publicado el 13 julio, s.p.

RESTREPO Eduardo (2001). "Hacia los estudios de las Colombias negras, texto realizado para Coloquio sobre Estudios Afrocolombianos”. Universidad del Cauca, Popayán. Octubre 24 -26 del 2001, s.p. [En línea http://www.banrepcultural.org/sites.... Consultado el 23 de marzo 2016] RODRIGUEZ Guadalupe (2011). «"El oro de Colombia: rebelión social contra explotaciones mineras sin control »”, World Rainforest Movement, Boletín 167, pp.1-6. [En línea http://wrm.org.uy/otherrelevant-information/el-oro-de-colombia-rebelion-social-contra-explotaciones-mineras-sincontrol/. Consultado el 24 de Marzo 2016]

SHOUSE TOURINO Corey (2009). "Fed by Any Means Necessary: Omnivorous Negritude and the Transnational Semiotics of Afro-Colombian Blackness in the Work of Liliana Angulo". Human Rights and Latin American Cultural Studies. Ed. Ana FORCINITO and Fernando ORDÓÑEZ. Hispanic Issues 4.1 (2009): pp. 228-246. [En línea http://spanport.cla.umn.edu/publications/ HispanicIssues/pdfs/SHOUSE.pdf. Consultado el 25 marzo 2016] TALPADE MOHANTY Chandra (1991). “Under western eyes: Feminist Scholarship and Colonial Discourses" en Chandra Talpade MOHANTY, Ann RUSSO, Lourdes TORRES, Third Wolrd Women and The Politics Of Feminism, Indiana University Press, pp. 52-79.

VARGAS Victor Manuel (2004). "Las africanas se blanquen”. El Tiempo, Bogotá, Colombia, 26 Julio, s.p.

WILLIS OBREGON, María Emma (2004). Las trayectorias femeninas y feministas hacia lo público en Colombia (1970-200), Tesis de Doctorado en Filosofía, dirigida por Henry Dietz, Austin, Universidad de Texas.

\section{NOTAS}

1. La ley 70 de 1993 define la Comunidad negra como el conjunto de familias de ascendencia afrocolombiana que poseen una cultura propia, comparten una historia y tienen sus propias tradiciones y costumbres dentro de la relación campo poblado, que revelan y conservan conciencia de identidad que las distinguen de otros grupos étnicos. (artículo 2, parágrafo 5).

2. Información tomada de la página web de El Observatorio, iniciativa de la Coordinación Regional del Pacífico Colombiano que cuenta con el soporte técnico y académico de la FUCLA y el apoyo técnico y conceptual del CINEP / Programa por la Paz.

3. No reconociendo las advertencias lanzadas por la Diócesis de Quibdó sobre la inminencia de confrontaciones armadas en Bojayá, el Estado no envía fuerzas de control para proteger este municipio considerado por las Autodefensas Unidas de Colombia -AUC- como un bastión de la gerrilla de las FARC. Desde finales de abril de 2002, los combates se desplazaron a zonas habitadas por civiles hasta llegar al municipio de Bojayá, donde 300 personas se refugiaron en la Iglesia, 100 en la casa cural y 100 más en la casa de las Misioneras Agustinas. El día 2 de mayo de 2002, un cilindro-bomba "rompió el techo de la iglesia, impacto contra el altar y estalló, detonando su carga de explosivos y de tralla y produciendo una gran devastación: en el suelo y hasta en los muros quedo la evidencia de los cuerpos desmembrados o totalmente deshechos, y la sangre manchó el lugar; mezclándose y perdiéndose entre los escombros". Valga resaltar que las la población del Pacífico no ha sido solamente atacada por la guerrilla, han sufrido también 
agresiones violentas por parte de los narcotraficantes y de los paramilitares como fue en el caso de las Casas de Pique en Buenaventura en el año 2000. Ver (MARTINEZ HERNANDEZ, 2014: s.p)

4. Diccionario de la Real Academia Española. Consultado en línea.

5. "Nieves es la empleada de servicio doméstico, de color - casi siempre, en este sector del país que tiene la nobleza de su raza. Alegre y confiada, con esa ingenuidad propia de la muchacha crecida lejos de la ciudad y con la mentalidad del que solo alcanza dos años de escuela. Las escenas domésticas, trasladas al papel, las recibimos (amas de casa) con una sonrisa. Sentimiento de "reconciliación" y gran aprecio - en el fondo - de aquella sirvienta de color, que con su delantal a cuadros y sus "churquitos" en la cabeza, ha salido trazar un puente de simpatía, entre las amas de su casa y su gremio. Detrás de Nieves esta Consuelo Lago, dándole con su plumilla y su gran imaginación. Lago, Apellido español vinculado a Cali, hace muchos años, que al mencionarlo nos hace pensar a don Manuel y don Pepe, vinculados a la banca..." (MORRIS, 1968: 11).

6. Tumaqueña es el gentilicio utilizado para las personas nacidas en Tumaco, municipio del departamento de Nariño, al sur occidente de Colombia lindado con el océano Pacífico.

7. Para profundizar en la manera en qué la diáspora configuró la identidad afroamericana consultar Routes: Travel and Translation in the Late Twentieth Century de James Clifford y The Black Atlantic: modernity and double consciousness de Paul Gilroy.

8. "La nación es una comunidad política imaginada como inherentemente y limitada. Es imaginada porque aún los miembros de la nación más pequeña no conocerán jamás a la mayoría de sus compatriotas, no lo verá ni oirá siquiera hablar de ellos, pero en la mente de cada uno vive la imagen de una comunión. p. 23). La nación de imagina es limitada porque incluso la mayor de ellas, que alberga tal vez a mil millones de seres humanos vivos, tiene fronteras finitas, aunque elásticas, más allá de las cuales se encuentras otras naciones. Por último, se imagina como comunidad porque, independientemente de la desigualdad y al explotación que en efecto puedan prevalecer en cada caso, la nación se concibe siempre como un compañerismo profundo, horizontal. p. 25.

9. Las Palenqueras provienen de San Basilio de Palenque, uno de los primeros poblados fundados por esclavos fugitivos. Identificadas públicamente como aquellas mujeres que visten ropa de colores y venden frutas frescas, las palanqueras recogen, al lado de las abuelas y de las madres, toda una herencia ancestral transmitida a través de la oralidad y la congregación de redes familiares y comunitarias.

\section{ÍNDICE}

Mots-clés: art contemporain, photographie, identité afrocolombienne, genre, stéréotypes Palabras claves: arte contemporáneo, fotografía, identidad afrocolombiana, género, estereotipos 


\section{AUTOR}

\section{ADRIANA PENA MEJÍA}

Candidata a doctorado, actualmente realizo una tesis sobre la configuración de la identidad

femenina en Colombia, bajo la dirección de la profesora Laurence Bertrand Dorléac. Sciences Po Paris: Historia del arte. 